\title{
Effectiveness of SVR 12 in Hepatitis C Subjects Attending Tertiary Care Hospital in Lahore-Pakistan: an Observational Data
}

\author{
Muddasir Hassan Abbasi, ${ }^{1, *}$, Adil Farooq ${ }^{1}$, Muhammad Babar khawar ${ }^{2,3, *}$, Nasir Yousaf ${ }^{1}$ \\ Muhammad Khalil Ahmad Khan', Sana Fatima', Nadeem Sheikh ${ }^{3, *}$ \\ ${ }^{1}$ Department of Zoology, University of Okara, Punjab-Pakistan. \\ ${ }^{2}$ Department of Zoology, Faculty of Sciences, University of Central Punjab (UCP), Lahore-Pakistan. \\ ${ }^{3}$ Department of Zoology, Cell, and Molecular Biology Lab, University of the Punjab, Lahore-Pakistan.
}

Authors' Contributions

1, 3, 7 Conception \& Study design, Drafting of Manuscript, Critical Review.

2, 4 Data Collection \& Processing, Data Analysis and/or Interpretation. Drafting of Manuscript.

5 Data Collection \& Processing, Data Analysis and/or Interpretation.

6 Data Collection \& Processing, Data Analysis and/or Interpretation, Critical Review.

\section{Acknowledgement}

The authors are thankful to the Vice-

Chancellor, University of Okara, Okara,

Pakistan, for providing financial support for the accomplishment of this study.

\section{Article info.}

Received: November 21, 2020

Accepted: May 08, 2021

Funding Source: Nil

Conflict of Interest: Nil

Cite this article: Abbasi MH, Faroog A, khawar MB, Yousaf N, Khan MKA, Fatima $S$, Sheikh N. Effectiveness of SVR 12 in Hepatitis C Subjects Attending Tertiary Care Hospital in Lahore-Pakistan: an Observational Data. RADS J Pharm Pharm Sci. 2021; 9(1):40-46.

*Address of Correspondence Author: muddygcs@gmail.com

\begin{abstract}
A B S TR AC T
Introduction: In Pakistan, for the patients of Hepatitis C virus (HCV), DirectActing Antiviral (DAA) therapy for 12 weeks and 24 weeks had been reported to be highly efficacious for genotype 3 . We currently carried out an observational study to predict the rate of efficacy of sofosbuvir and ribavirin in hepatitis $C$ patients to establish concrete or authentic data on this combination of DAA for long-term treatment.
\end{abstract}

Materials and Method: Among 2000 subjects who attended tertiary care unit in Lahore-Pakistan from November 2018 to February 2019, 1990 satisfied the criteria set for the present investigation i.e. SVR12 after being treated with sofosbuvir and ribavirin combination.

Results: It was noted that genotype 3 a were more common among all the subjects under observation with $50.65 \%$ (1008/1990) in females and $49.35 \%$ $(982 / 1990)$ in males. Overall efficacy analysis was found to be $95.4 \%$ $(1900 / 1990)$ in patients while the moderate response was noted in elderly subjects including both genders (61-90 years). DAA responders (male: female percentages) shown the following stats; 66.63 (42/66):36.36 (24/66) in 11-20 years, $56.6(240 / 424): 43.39 \quad(184 / 424)$ in 21-30 years and $44.73(272 / 608): 55.27(336 / 608)$ in 31-40 years .

Conclusion: Collectively, this combinational drug therapy was observed to be successful among the Pakistani population. However, more comprehensive follow-up studies are needed on a larger pool of population nationwide to check only this combinational therapy (sofosbuvir and ribavirin) would be beneficial or not? Or next-generation DAA regimes would be the choice for the Pakistani population.

Keywords: Direct-acting antivirals (DAA), Hepatitis $C$ virus (HCV), Sustained viral response (SVR), Sofosbuvir, Ribavirin.

\section{INTRODUCTION}

The global burden of the Hepatitis $\mathrm{C}$ virus (HCV) increases day by day whereas most people lost their lives if untreated or taken it casually. Poor hygienic control and liver metabolized medications are also reported to be responsible for the cause the Hepatitis C [1, 2]. Pakistan has one of the highest rates of this disease and more than 10 million population in this country is known to be infected with HCV. Among the 
known genotypes (1 to 6 ), 3a being most prevalent in Pakistan and were difficult to treat $[3,4]$. Most HCV patients have developed liver cirrhosis in the younger age group (25 to 35 years) accompanied with a severe complication like jaundice hepatocellular carcinoma (HCC), and if any other co-infection under treatment complication may lead to death.

It has been revealed that interferon alone is not efficient because of low efficacy rate while in some patients relapse, loss of appetite and muscle pain has also been reported. Till the end of 2011, HCV treated by interferon and in combination with ribavirin is considered to be the best. Due to reported side effects, a direct-acting antiviral (DAA) regimen represents a breakthrough and milestone that has completely changed the landscape of HCV treatment. Hence, sofosbuvir being the first DAA nucleotide inhibitor reported as being a choice of treatment for chronic hepatitis C. Concurrently, Sofosbuvir and ribavirin combination therapy for 12 and 24 weeks is highly efficacious for genotype 1and genotype 3 active against both genotype [4].

The current study was undertaken from a different region of Pakistan to predict the rate of efficacy of sofosbuvir (DAA) and ribavirin in hepatitis $C$ patients due to the lack of concrete or authentic data to use this treatment option on a long term basis in this region.

\section{MATERIALS AND METHODS}

\section{Ethical issues and settings}

This potential cross-sectional study was conducted for four-month from November 2018 to February 2019. A total of 2000 patients were enrolled, informed about the study, and were explained that their record was kept safe and will be used for research purpose only. All the enrolled patients were categorized based on age (younger to older) into eight groups $(A-H)$. A; 11 - 20, B; 21-30, C; 31-40, D; 41-50, E; 51-60, F; 61-70, G; 71-80, H; 81-90. A specially designed questioner was made to obtain the basic information regarding the patient lifestyle before collecting the subject's blood sample.

\section{Exclusion and inclusion criteria}

All the naïve, recurring HCV subjects and all HCV positive subjects who had received 12 weeks long therapy of DAA were included in the study while all
HBV patients and HCV subjects up to 7 years of age though HCV positive were excluded from the study.

\section{Statistical analysis}

All the statistical analysis was performed on prism graph 5. The statistical significance of the difference among different groups was measured using the student t-test, the data were considered significant when the $p$-value was $<0.05\left({ }^{*}\right),<0.01\left(^{* *}\right)$, and $\left.0.001{ }^{* * *}\right)$.

\section{RESULTS}

The current study included a total of two thousand patients among them six subjects were positive for HBV while four were positive for HCV under (1-10) year of age group (data not included). The rest of the 1990 subjects have been confirmed positive for HCV with genotype $3 \mathrm{a}$. Among these subjects, 982 were males $(49.35 \%)$ and the remaining were females 1008 (50.65\%). Results had shown that little increase in the number of $\mathrm{HCV}$ in females as compared to males. Group-wise percentages of males and females in different age groups is presented as Group A: $66.63(42 / 66)$ and $36.36(24 / 66)$ in 11-20 years, group B: $56.61(240 / 424)$ and $43.39(184 / 424)$ in 21-30 years, group C: $44.73(272 / 608)$ and 55.27 (336/608) in 31-40 years, group D: 45.94 (221/481) and 54.06 (260/481) in 41-50 years, group E: 52.41 (130/248) and $45.58(118 / 248)$ in $51-60$ years group $F$ : $67.24(39 / 58)$ and $32.75(19 / 58)$ of $61-70$ years, group G: $30.76(4 / 13)$ and $69.24(9 / 13)$ in (71-80) year, while group $\mathrm{H}$ represent: year of only $2(100 \%)$ female subjects (81-90 years) (Figure 1; Table 1).

The overall response rate of $95.4 \%$ of total 1990 patients were successfully treated with the therapy of sofosbuvir and ribavirin, whereas 90 subjects (patients) did not show response towards (DAA) sofosbuvir and ribavirin therapy. The non-responding subjects and their respective percentages are shown in (Figure 2; Table 1 \& 2) wherein the group-wise percentage of male; female with different age groups; Group A: 66.66(2/3); 33.34(1/3) in 11-20 years. Group B: $38.46(5 / 13), 61.34(8 / 13)$ in 21-30 years. Group C: $40(12 / 30) ; 60(18 / 30)$ in 31 - 40 years. Group D: $39.13(9 / 23)$; $60.87(14 / 23)$ in $41-50$ years. Group E: $30(3 / 10) ; 70(7 / 10)$ in $51-60$ years. Group F: 22.22(2/9); 77.78(7/9) in 61-70 years. Group F \& G single male and single female $71-90$ years respectively. 
Regarding gender-wise distribution in responders of various groups; group $A-B$ has shown; male > females, group C-D has shown females > males, group E-F male > females, while group $\mathrm{G}-\mathrm{H}$ has shown females $>$ males (Figure 3).

Table 1. Treatment response in enlisted patients (male \& female) after receiving SVR12 week-long sofosbuvir-based regimen $(n=1900)$.

Responders

\begin{tabular}{|c|c|c|c|c|}
\hline Sr. No & $\begin{array}{c}\text { Age group } \\
\text { Years }\end{array}$ & Male & Female & Total \\
\hline $\mathbf{1}$ & $11-20$ & $42(63.63 \%)$ & $24(36.36 \%)$ & 66 \\
\hline $\mathbf{2}$ & $21-30$ & $240(56.60 \%)$ & $184(43.39 \%)$ & 424 \\
\hline $\mathbf{3}$ & $31-40$ & $272(44.73 \%)$ & $336(55.27 \%)$ & 608 \\
\hline $\mathbf{4}$ & $41-50$ & $221(45.94 \%)$ & $260(54.06 \%)$ & 481 \\
\hline $\mathbf{5}$ & $51-60$ & $130(52.41 \%)$ & $118(45.58 \%)$ & 248 \\
\hline $\mathbf{6}$ & $61-70$ & $39(67.24 \%)$ & $19(32.75 \%)$ & 58 \\
\hline $\mathbf{7}$ & $71-80$ & $4(30.76 \%)$ & $9(69.24 \%)$ & 13 \\
\hline $\mathbf{8}$ & $81-90$ & 0 & $2(100 \%)$ & 2 \\
\hline & Total & $\mathbf{9 4 8}$ & $\mathbf{9 5 2}$ & $\mathbf{1 9 0 0}$ \\
\hline
\end{tabular}

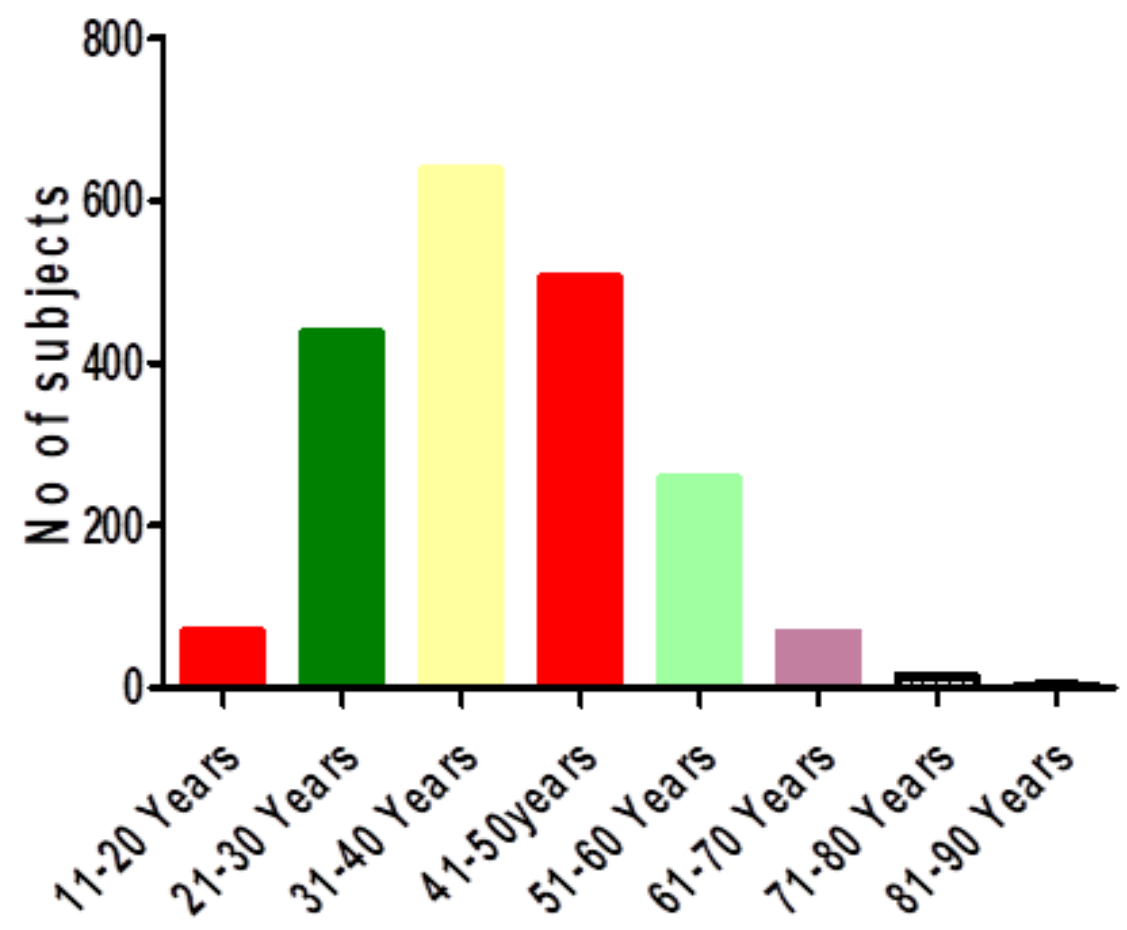

Figure 1. Age-wise distribution of HCV prevalence of all the enlisted subjects ( $n=1990)$ in the current study. 


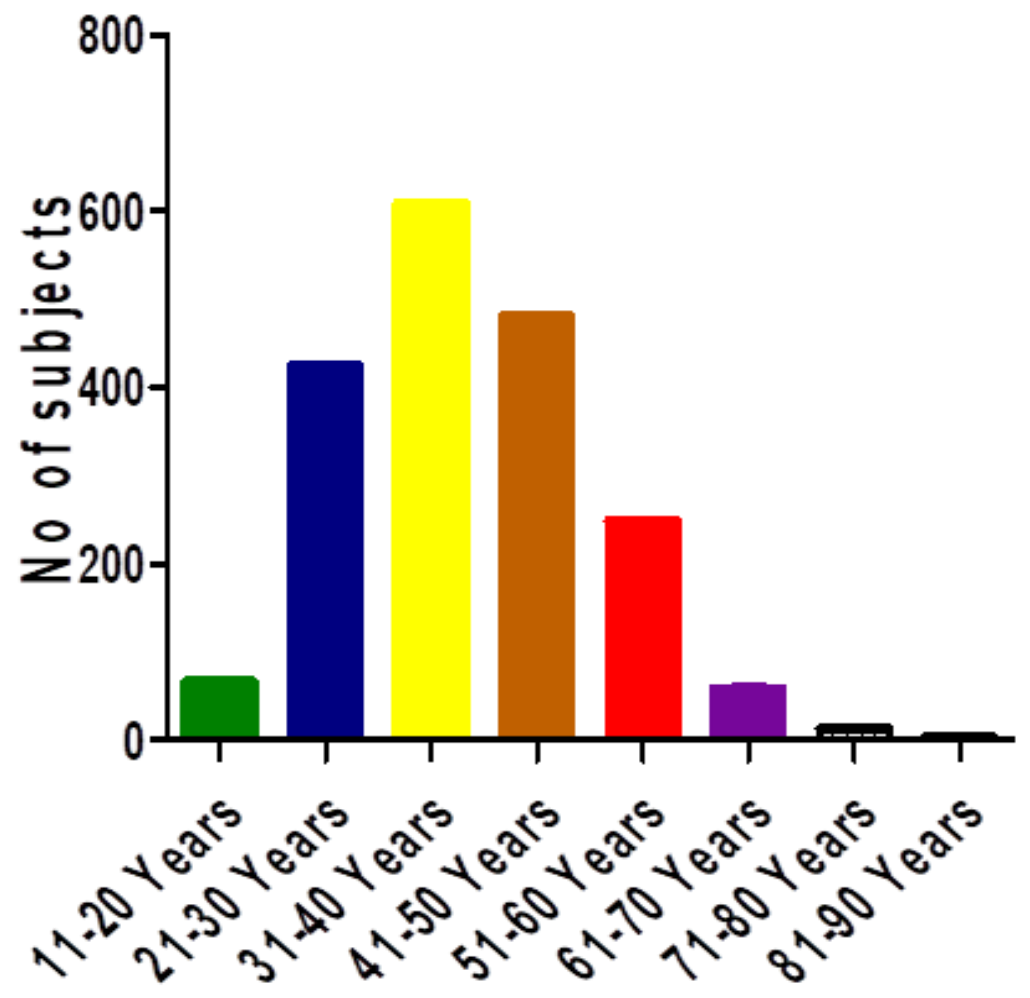

Figure 2. Prevalence of HCV in all the enlisted subjects of the current study 1900 patients A-H groups (11-90 years).
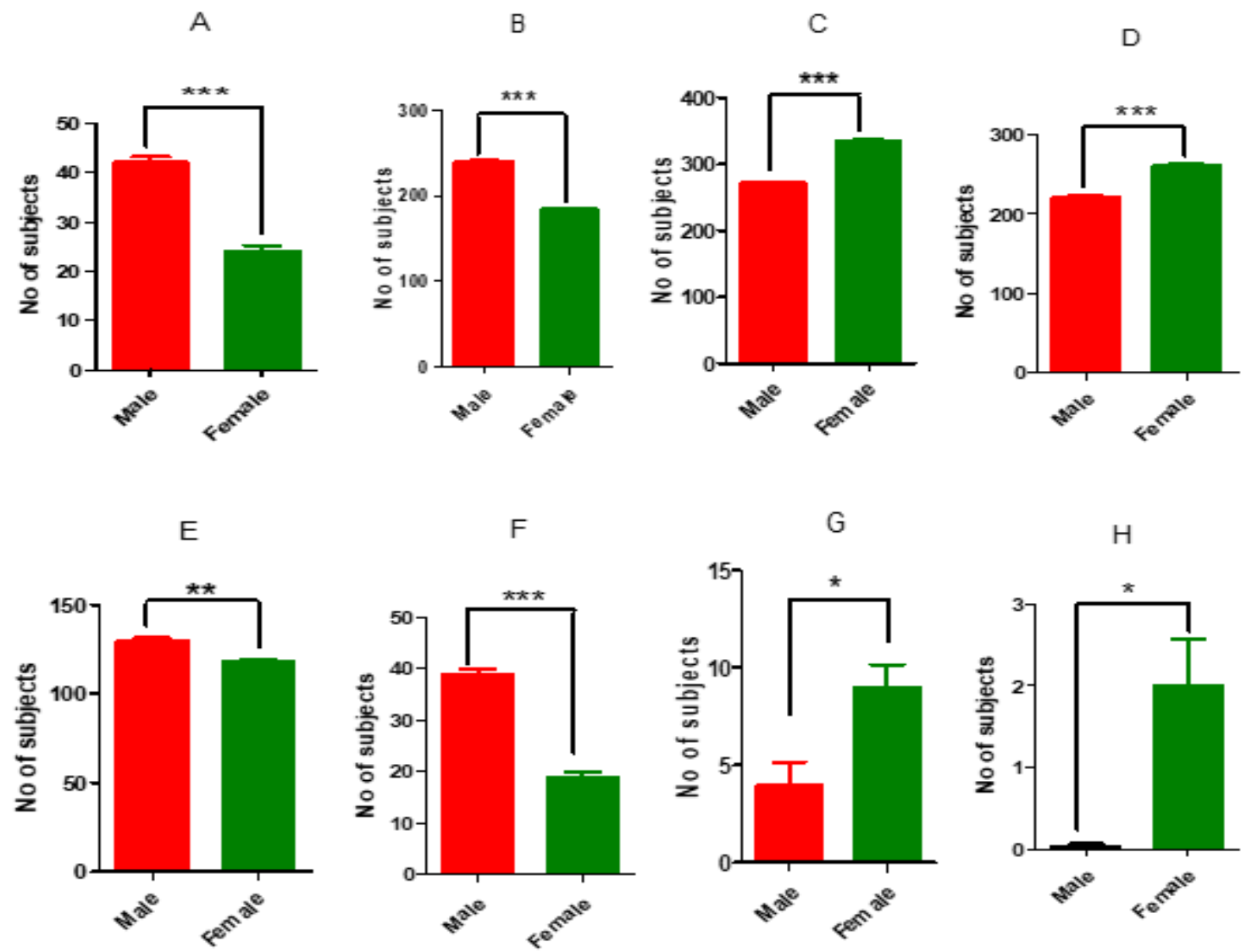

Figure 3. Gender-wise distribution of HCV responder against DAA from Pakistani population. 
Table 2. Shows the HCV non-responders patient against the sofosbuvir. NON RESPONDERS

\begin{tabular}{|c|c|c|c|c|}
\hline Sr No & Age groups (Years) & Male & Female & Total \\
\hline $\mathbf{1}$ & $11-20$ & $2(66.66 \%)$ & $1(33.33 \%)$ & 3 \\
\hline $\mathbf{2}$ & $21-30$ & $5(38.46 \%)$ & $8(61.54 \%)$ & 13 \\
\hline $\mathbf{3}$ & $31-40$ & $12(40 \%)$ & $18(60 \%)$ & 30 \\
\hline $\mathbf{4}$ & $41-50$ & $9(39.13 \%)$ & $14(60.87 \%)$ & 23 \\
\hline $\mathbf{5}$ & $51-60$ & $3(30 \%)$ & $7(70 \%)$ & 10 \\
\hline $\mathbf{6}$ & $61-70$ & $2(22.22 \%)$ & $7(77.78 \%)$ & 9 \\
\hline $\mathbf{7}$ & $71-80$ & $1(100 \%)$ & 0 & 1 \\
\hline $\mathbf{8}$ & $81-90$ & 0 & $1(100 \%)$ & $\mathbf{9 0}$ \\
\hline & Total & $\mathbf{3 4}$ & $\mathbf{5 6}$ & \\
\hline
\end{tabular}

\section{DISCUSSION}

This current observational study was performed to scrutinize the response rate of the sofosbuvir-based regime against $\mathrm{HCV}$ subjects attending tertiary care hospitals in Lahore Pakistan. Sofosbuvir is known to be a well-tolerated nucleotide polymerase inhibitor with activity against $3 a$ genotypes with improved SVR rate. Sofosbuvir and ribavirin effectiveness in HCV patients infected with 3a genotype is also reported by various workers[6-8]. Our results have also shown a significantly high response rate in the Pakistani population while a small fraction of non-responders also noted. Other studies based on the Pakistani population have also exhibited an overall response rate of $\geq 90 \%$ [9-11]. The response rate $90 \%$ and $10 \%$ relapse rate during the treatment with sofosbuvir and ribavirin in 3a-HCV patients [12, 13]. SVR achieved about $97 \%$ in Japanese patients after being treated with sofosbuvir and ribavirin [14]. Moreover, a low incidence of late recurrence HCV had been observed by Sarrazin, et al. (2016) [15].

In previous studies, non-responsiveness is more common in cirrhotic as well as interferon-treated patients but our observations are not consistent with this finding because all the patients included in our study were non-cirrhotic and hadn't received any prior treatment [16]. The Nucleotide analog (Sofosbuvir) directly acts on the virus and inhibits the NS5B polymerase coding region of $\mathrm{HCV}$ and is held to be a more effective direct-acting antiviral drug. Rare side effects of Sofosbuvir have been observed as compared to interferon which makes it's a choice of treatment option [17]. In the current study, the overall SVR-12 rate in all the studied groups $(\mathrm{A}-\mathrm{H})$ was reported to be 95.6, 97, 95, 95, 96, 86.5, 92, and 66 percentages respectively. Sofosbuvir and ribavirin combination therapy for hepatitis $\mathrm{C}$ subjects infected with genotype $3 a$ seems to be more effective in the current study.

The elimination of the hepatitis $\mathrm{C}$ disease from the Pakistani population is inspiring where most of the patients are infected with HCV genotype 3[18-20]. In the present study, a large number of population also reported to be non-responder, this might be due to resistant associated variants (RAVs) in which some specific amino acid substitutions and the different combination is effective for retreatment. It is also seen that elderly patients may be immune-compromised [21-23]. The possible treatment for non-responders after the failure of sofosbuvir+ ribavirin is the addition of daclatasvir [24].

Combination therapy of sofosbuvir and ribavirin for 24 weeks (SVR24) has shown a successful result $\geq 0$ f $90 \%$. According to our observation DAA therapy shown excellent results in HCV patients with genotype 3a. Collectively, this combinational drug therapy was observed to be successful among the Pakistani population. However, more comprehensive follow-up studies are needed on a larger pool of population nationwide to check only this combinational therapy (sofosbuvir and ribavirin) would be beneficial or not? Or next-generation DAA regimes would be the choice for the Pakistani population. 


\section{CONCLUSION}

Collectively, this combinational drug therapy was quite successful among the Pakistani population. However, more comprehensive follow-up studies are needed on a larger pool of population nationwide to check only this combinational therapy (sofosbuvir and ribavirin) would be beneficial or not? Or nextgeneration DAA regimes would be the choice for the Pakistani population.

\section{Conflict of interests}

The authors declare no conflict of interests.

\section{REFERENCES}

1. Denniston MM, Jiles RB, Drobeniuc J, Klevens RM, Ward JW, McQuillan GM, Holmberg SD. Chronic hepatitis $C$ virus infection in the United States, national health and nutrition examination survey 2003 to 2010. Annals of internal medicine. 2014; 160(5):293-300.

2. Armstrong GL, Wasley A, Simard EP, McQuillan GM, Kuhnert WL, Alter MJ. The prevalence of hepatitis $C$ virus infection in the United States, 1999 through 2002. Annals of internal medicine. 2006; 144(10):705-14.

3. Umar M, Bilal M. Hepatitis C, a mega menace: a Pakistani perspective. J Pak Med Stud. 2012; 2(2):68-72.

4. Ampuero J, Romero-Gomez M, Reddy KR. HCV genotype 3-the new treatment challenge. Alimentary pharmacology \& therapeutics. 2014; 39(7):686-98.

5. Manzoor S, Younis S, Hussain M, Ehsan F, Sheikh $\mathrm{N}$, Abbasi MH. Efficacy of direct-acting anti-viral therapy on chronic, naïve hepatitis $C$ virus patients of Punjab, Pakistan: a cross-sectional study. Journal of biological regulators and homeostatic agents. 2019; 33(1):105-8.

6. Steinebrunner N, Sprinzl MF, Zimmermann $T$, Wörns MA, Zimmerer T, Galle PR, Stremmel W, Eisenbach C, Stein K, Antoni C, Schattenberg JM. Early virological response may predict treatment response in sofosbuvir-based combination therapy of chronic hepatitis $\mathrm{c}$ in a multi-center "real-life" cohort. BMC gastroenterology. 2015; 15(1):1-8.

7. Liu X, Wang Y, Zhang G, Li N, Zhu Q, Chang H, Han Q, Lv Y, Liu Z. Efficacy and safety of sofosbuvir-based therapy for the treatment of chronic hepatitis $\mathrm{C}$ in treatment-naïve and treatment-experienced patients. International journal of antimicrobial agents. 2014; 44(2):14551.

8. Manzoor S, Younis S, Hussain M, Ehsan F, Sheikh $\mathrm{N}$, Abbasi $\mathrm{MH}$. Efficacy of direct-acting anti-viral therapy on chronic, naïve hepatitis $C$ virus patients of Punjab, Pakistan: a cross-sectional study. Journal of biological regulators and homeostatic agents. 2019; 33(1):105-8.

9. Akhter TS, Umar M, Umar S, Nisar G, Shehzad A, Naseer A, Ahmad S, Minhas Z, Khan JZ, Rasheed MI. Su1461 trends of sofosbuvir treatment for chronic hepatitis $C$ infection in genotype 3 patients-an experience from Pakistan. Gastroenterology. 2016; 150(4):S1106.

10. Umar M, Khaar HT, Akhter TS, Aslam F, Ahmad SI, Asghar RM, Khurram M, Hussain T, Salamat A, Khan AA, Minhas ZM. Diagnosis, Management And Prevention Of Hepatitis C In Pakistan 2017. Journal of Ayub Medical College, Abbottabad: JAMC. 2016; 28(4 Suppl 1):S839-82.

11. Mansoor VB, Ahmed U, Jahanzaib M, Ali Z, Haroon MA, Ahmed H, Munim A. End treatment response in chronic hepatitis $C$ patients to sofosbuvir and ribavirin. Annals of PIMS ISSN. 2016; 1815:2287.

12. Zeuzem S, Dusheiko GM, Salupere R, Mangia A, Flisiak R, Hyland $\mathrm{RH}$, Illeperuma A, Svarovskaia E, Brainard DM, Symonds WT, Subramanian GM. Sofosbuvir and ribavirin in HCV genotypes 2 and 3. New England Journal of Medicine. 2014 May 22;370(21):1993-2001.

13. Jacobson IM, Gordon SC, Kowdley KV, Yoshida EM, Rodriguez-Torres M, Sulkowski MS, Shiffman ML, Lawitz E, Everson G, Bennett M, Schiff E. Sofosbuvir for hepatitis $C$ genotype 2 or 3 in patients without treatment options. New England journal of medicine. 2013; 368(20):1867-77.

14. Omata $M$, Nishiguchi $S$, Ueno $Y$, Mochizuki $H$, Izumi N, Ikeda F, Toyoda H, Yokosuka O, Nirei K, Genda $T$, Umemura T. Sofosbuvir plus ribavirin in Japanese patients with chronic genotype $2 \mathrm{HCV}$ infection: an open-label, phase 3 trial. Journal of Viral Hepatitis. 2014 Nov;21(11):762-8.

15. Sarrazin C, Isakov V, Svarovskaia E, Hedskog C, Martin R, Chodavarapu K, Brainard DM, Miller MD, Mo H, Molina JM, Sulkowski MS. Late relapse versus $\mathrm{HCV}$ reinfection in patients with sustained virologic response after sofosbuvir-based therapies. Clinical Infectious Diseases. 2016 Oct 15:ciw676.

16. Sulkowski MS, Gardiner DF, Rodriguez-Torres M, Reddy KR, Hassanein T, Jacobson I, Lawitz E, Lok AS, Hinestrosa F, Thuluvath PJ, Schwartz H. Daclatasvir plus sofosbuvir for previously treated 
or untreated chronic HCV infection. New England Journal of Medicine. 2014 Jan 16;370(3):211-21.

17. Iqbal S, Yousuf MH, Yousaf MI. Dramatic response of hepatitis $\mathrm{C}$ patients chronically infected with hepatitis $C$ virus genotype 3 to sofosbuvir-based therapies in Punjab, Pakistan: A prospective study. World journal of gastroenterology. 2017 Nov 28;23(44):7899.

18. Iqbal S, Ahmad R, Yousaf MH, Mumtaz A, Amine D, Rasool G, Manzoor A. Assessment of major genotypes and subtypes of Hepatitis $C$ virus. Professional Med J. 2007; 14:266-71.

19. Khan N, Akmal M, Hayat M, Umar M, Ullah A, Ahmed I, Rahim K, Ali S, Bahadar S, Saleha S. Geographic distribution of hepatitis C virus genotypes in pakistan. Hepatitis monthly. 2014; 14(10).

20. Idrees M, Riazuddin S. Frequency distribution of hepatitis $C$ virus genotypes in different geographical regions of Pakistan and their possible routes of transmission. BMC infectious diseases. 2008; 8(1):1-9.
21. Osinusi A, Kohli A, Marti MM, Nelson A, Zhang X, Meissner EG, Silk R, Townsend K, Pang PS, Subramanian GM, McHutchison JG. Re-treatment of chronic hepatitis $C$ virus genotype 1 infection after relapse: an open-label pilot study. Annals of internal medicine. 2014; 161(9):634-8.

22. Tseng CW, Chang TT, Tzeng SJ, Hsieh YH, Hung TH, Huang HT, Wu SF, Tseng KC. Association of sustained virologic response with reduced progression to liver cirrhosis in elderly patients with chronic hepatitis C. Clinical interventions in aging. 2016;11:327.

23. Rheem J, Sundaram V, Saab S. Antiviral therapy in elderly patients with hepatitis $C$ virus infection. Gastroenterology \& hepatology. 2015 May;11(5):294.

24. Shah ND, Fried MW. Treatment options of patients with chronic hepatitis $C$ who have failed prior therapy. Clinical liver disease. 2016 Feb;7(2):40-4.

This is an Open Access article distributed under the terms of the Creative Commons Attribution License (http://creativecommons.org/licenses/by/4.0), which permits unrestricted use, distribution, and reproduction in any medium, provided the original work is properly cited. 